\title{
New steps forward for obstructive sleep apnoea in the era of precision medicine
}

\author{
Yüksel Peker (10) ${ }^{1,2,3}$ and Patrick J. Strollo Jr (10 ${ }^{3,4}$
}

Affiliations: ${ }^{1}$ Dept of Pulmonary Medicine, Faculty of Medicine, Marmara University, Istanbul, Turkey. ${ }^{2}$ Dept of Clinical Sciences, Respiratory Medicine and Allergology, Faculty of Medicine, Lund University, Lund, Sweden. ${ }^{3}$ Division of Pulmonary, Allergy, and Critical Care Medicine, University of Pittsburgh School of Medicine, Pittsburgh, PA, USA. ^VA Pittsburgh Health System, Pittsburgh, PA, USA.

Correspondence: Yüksel Peker, Dept of Pulmonary Medicine, School of Medicine, Marmara University, Pendik Education and Research Hospital, Sleep Medicine Center, Pendik, Istanbul, Turkey.

E-mail: yuksel.pekeramed.lu.se

@ERSpublications

A report from a working group on obstructive sleep apnoea discusses the current challenges in the field and proposes topics for future research http://ow.ly/vcAi30kW8V5

Cite this article as: Peker Y, Strollo PJ Jr. New steps forward for obstructive sleep apnoea in the era of precision medicine. Eur Respir J 2018; 52: 1801240 [https://doi.org/10.1183/13993003.01240-2018].

Obstructive sleep apnoea (OSA) is a progressive disorder characterised by repeated upper-airway collapse during sleep that leads to intermittent hypoxia and hypercapnia, fragmented sleep, fluctuations in blood pressure and increased sympathetic nervous system activity [1]. Population studies in the early 1990s found OSA (defined by an apnoea-hypopnoea index (AHI) $>5$ events $\cdot h^{-1}$ ) in $9 \%$ of middle-aged women and $24 \%$ of middle-aged men [2]. Later studies have demonstrated a higher occurrence (in $17 \%$ of women and $34 \%$ of men), which was mainly attributed to increasing body mass index in the general population over time [3]. Notably, the HypnoLaus study, which is to date the largest European epidemiological study [4], demonstrated that $61 \%$ of women and $84 \%$ of men in an unselected general cohort of 2121 adults had OSA based on the polysomnographic AHI cut-off level of 5 events $h^{-1}$ and on the recent hypopnoea definitions of the American Academy of Sleep Medicine [5]. HeInzer et al. [4] concluded in the HypnoLaus study that the prevalence of OSA was highly dependent on technical procedures (i.e. nasal cannula recording subtle breathing variation for scoring hypopnoeas) as well as the hypopnoea definition (3\% desaturations instead of $4 \%$ desaturations, and/or arousals) [5]. There have been significant changes in the definition of OSA over time, with research reports suggesting an independent association between OSA and metabolic and cardiovascular disease (CVD), especially in the sleep clinic cohorts with self-reported excessive daytime sleepiness (EDS) [6-8]. The first choice for treatment of OSA is positive airway pressure (PAP), which has been demonstrated to reduce EDS and improve the quality of life [9]. In patients with CVD who do not report EDS, adherence to PAP treatment has been challenging in the recent randomised controlled trials (RCTs) $[10,11]$. It has been shown that OSA has different clinical phenotypes based on anatomical [12] or physiological [13] features, or a mixture of both [14]. The degree of EDS, sex differences in presentation of symptoms and comorbid conditions may vary substantially [15]. OSA during rapid eye movement sleep has been linked to hypertension among individuals who otherwise have normal total AHI values [16], suggesting that this subgroup of patients deserve attention with regard to CVD outcomes [17]. Despite increasing research evidence linking OSA with metabolic and cardiovascular outcomes, and the beneficial effect of PAP treatment in the observational studies [8, 18], there is still a lack of convincing data from the RCTs that treating this disorder reduces the cardiovascular risk. Ethical concerns regarding randomisation of symptomatic OSA patients to no treatment have influenced the design of long-term RCTs during the last decade, focusing on asymptomatic or minimally 
symptomatic OSA patients $[10,11]$. The lack of a beneficial effect on cardiovascular outcomes in the intention-to-treat analysis in these populations has led to uncertainty regarding the role of PAP treatment in clinical cohorts with CVD or cerebrovascular disease and concomitant OSA [19-22].

In this issue of the European Respiratory Journal, RANDERATH et al. [23] report from an ad hoc working group of the Sleep Disordered Breathing Group of the European Respiratory Society and the European Sleep Research Society, who convened a consensus conference examining the current state of knowledge related to the diagnosis and treatment of OSA based on what were determined to be the most relevant publications in the previous 5 years. The current challenges in the field were discussed and topics were identified for future research: epidemiology, phenotyping, underlying mechanisms, prognostic implications, and optimal treatment of patients with OSA. RANDERATH et al. [23] concluded that a revision to the diagnostic criteria for OSA was required, to include factors that reflect different clinical and pathophysiological phenotypes, and relevant comorbidities such as nondipping nocturnal blood pressure. The group further concluded that current OSA severity thresholds should also be revised to reflect factors such as disparity in AHI between polysomnography and home sleep apnoea testing that does not include sleep stage measurements, in addition to the poor correlation between AHI and EDS. The authors also suggested that the management decisions should be linked to the underlying clinical and pathophysiological phenotyping, addressing outcomes beyond the AHI.

RANDERATH et al. [23] should be commended for examining the important gaps of knowledge and exploring future opportunities for research and management of patients with OSA. In brief, 19 experts from 11 European countries, representing a spectrum of specialists in pulmonary medicine, neurology and psychiatry, in addition to basic and translational scientists, defined eight major topics: clinical phenotyping of OSA, assessment of disease severity, diagnostic algorithms/new tools, EDS and related driving risk, OSA and neuro-psychiatric disorders, outcomes of OSA, comorbid conditions in OSA, and optimum treatment. The report was based on the relevant papers on each respective topic during the previous 5 years, and the working subgroups were tasked to describe the most important clinical challenges and research priorities in the field of OSA for the next 5-10 years. The findings of the subgroup discussions were adjudicated by the participants utilising a Delphi consensus approach.

Regarding clinical phenotyping of OSA, the need for an individualised approach was identified. Conventional diagnostic procedures, pathophysiological phenotypes, clinical phenotypes and the assessment of target organ consequences were reviewed. Priorities for future research included redefining the role of polysomnography, addressing the clinical importance of the pathophysiological traits, cluster analysis in prospective clinical cohorts and translation of the OSA subtypes into personalised medicine [23]. As highlighted in another recent review [24], a unique objective index such as the AHI for the classification of the OSA severity does not consistently resolve the problem of patient classification and treatment selection. Using the Epworth Sleepiness Scale, a subjective measure, to evaluate one of the main symptoms of OSA, is imprecise. A molecular signature for EDS is needed in clinical practice and would be particularly useful in determining fitness to drive [23]. Some repetition is understandable in categorising the challenges and perspectives for the eight topics, primarily related to overlap. This project reflects the challenge of bringing experts from different European countries and disciplines together to achieve consensus regarding the diagnosis and clinical management of OSA patients. The consensus-based approach employing heterogeneous ad hoc working subgroups provides a unique perspective regarding personalised diagnostic and therapeutic approaches to OSA management. Other topics overlapping with sleep disordered breathing, such as central sleep apnoea (CSA) with Cheyne-Stokes respiration as well as hypoventilation, were excluded from the review, although shifting from OSA to CSA and vice versa is frequently observed in cardiovascular cohorts. The future perspectives frequently posed questions rather than solutions. Of note, one recent relevant paper that was not included among the reviewed references is worth mentioning [25]. This report provided a contextual framework for interpreting the results of recent studies, key clinical messages, and suggestions for future sleep and cardiovascular research [25]. As stated in the current article by RANDERATH et al. [23], as well as in other recent reviews [24, 26], future perspectives should consider individual risk factors, incorporate new multimodality treatments that also address adherence, and consider implementation of trials that are appropriately powered to target end-points and to support subgroup analyses. Strengthening collaboration among the cardiology, sleep medicine and clinical trial specialists would be beneficial [25]. These perspectives also reaffirm the concept of P4 medicine as a roadmap for improving care in OSA that is personalised, predictive, preventive and participatory in nature [27].

Conflict of interest: Y. Peker reports institutional grants from ResMed, and personal fees from BresoTec Inc. (for consultancy) and from Philips-Respironics (for lecturing), outside the submitted work. P.J. Strollo Jr reports institutional grants from Philips-Respironics, National Football League and PinMed; institutional grants and personal 
advisory fees from ResMed and Inspire Medical Systems; and personal advisory fees from Emmi Solutions, Jazz Pharmaceuticals, Itamar Medical and Seperation Design Group, outside the submitted work.

\section{References}

1 Young T, Palta M, Dempsey J, et al. Burden of sleep apnea: rationale, design, and major findings of the Wisconsin Sleep Cohort study. WMJ 2009; 108: 246-249.

2 Young T, Palta M, Dempsey J, et al. The occurrence of sleep-disordered breathing among middle-aged adults. N Engl J Med 1993; 328: 1230-1235.

3 Peppard PE, Young T, Barnet $\mathrm{JH}$, et al. Increased prevalence of sleep-disordered breathing in adults. Am J Epidemiol 2013; 177: 1006-1014.

4 Heinzer R, Vat S, Marques-Vidal P, et al. Prevalence of sleep-disordered breathing in the general population: the HypnoLaus study. Lancet Respir Med 2015; 3: 310-318.

5 Berry RB, Budhiraja R, Gottlieb DJ, et al. Rules for scoring respiratory events in sleep: update of the 2007 AASM Manual for the Scoring of Sleep and Associated Events. Deliberations of the Sleep Apnea Definitions Task Force of the American Academy of Sleep Medicine. J Clin Sleep Med 2012; 8: 597-619.

6 Marin JM, Carrizo SJ, Vicente E, et al. Long-term cardiovascular outcomes in men with obstructive sleep apnoea-hypopnoea with or without treatment with continuous positive airway pressure: an observational study. Lancet 2005; 365: 1046-1053.

7 Hedner J, Grote L, Bonsignore M, et al. The European Sleep Apnoea Database (ESADA): report from 22 European sleep laboratories. Eur Respir J 2011; 38: 635-642.

8 Javaheri S, Barbe F, Campos-Rodriguez F, et al. Sleep apnea: types, mechanisms, and clinical cardiovascular consequences. J Am Coll Cardiol 2017; 69: 841-858.

9 Engleman HM, Martin SE, Kingshott RN, et al. Randomised placebo controlled trial of daytime function after continuous positive airway pressure (CPAP) therapy for the sleep apnoea/hypopnoea syndrome. Thorax 1998; 53 : 341-345.

10 Peker Y, Glantz H, Eulenburg C, et al. Effect of positive airway pressure on cardiovascular outcomes in coronary artery disease patients with nonsleepy obstructive sleep apnea. The RICCADSA randomized controlled trial. Am J Respir Crit Care Med 2016; 194: 613-620.

11 McEvoy RD, Antic NA, Heeley E, et al. CPAP for prevention of cardiovascular events in obstructive sleep apnea. N Engl J Med 2016; 375: 919-931.

12 Lee RW, Sutherland K, Chan AS, et al. Relationship between surface facial dimensions and upper airway structures in obstructive sleep apnea. Sleep 2010; 33: 1249-1254.

13 Eckert DJ, White DP, Jordan AS, et al. Defining phenotypic causes of obstructive sleep apnea. Identification of novel therapeutic targets. Am J Respir Crit Care Med 2013; 188: 996-1004.

14 Owens RL, Edwards BA, Eckert DJ, et al. An integrative model of physiological traits can be used to predict obstructive sleep apnea and response to non positive airway pressure therapy. Sleep 2015; 38: 961-970.

15 Saaresranta T, Hedner J, Bonsignore MR, et al. Clinical phenotypes and comorbidity in European sleep apnoea patients. PLoS One 2016; 11: e0163439.

16 Mokhlesi B, Finn LA, Hagen EW, et al. Obstructive sleep apnea during REM sleep and hypertension. Results of the Wisconsin Sleep Cohort. Am J Respir Crit Care Med 2014; 190: 1158-1167.

17 Peker Y. REM sleep: a nightmare for patients with obstructive sleep apnea? Am J Respir Crit Care Med 2014; 190: 1088-1090.

18 Peker Y, Thunström E, Glantz H, et al. Outcomes in coronary artery disease patients with sleepy obstructive sleep apnoea on CPAP. Eur Respir J 2017; 50: 1700749.

19 Yu J, Zhou Z, McEvoy RD, et al. Association of positive airway pressure with cardiovascular events and death in adults with sleep apnea: a systematic review and meta-analysis. JAMA 2017; 318: 156-166.

20 Peker Y, Strollo PJ Jr. A meta-analysis of positive airway pressure treatment for cardiovascular prevention: why mix apples and pears? Evid Based Med 2017; 22: 218-219.

21 Martinez-Garcia MA, Campos-Rodriguez F, Javaheri S, et al. Pro: continuous positive airway pressure and cardiovascular prevention. Eur Respir J 2018; 51: 1702400.

22 McEvoy RD, Kohler M. Con: continuous positive airway pressure and cardiovascular prevention. Eur Respir 2018; 51: 1702721.

23 Randerath W, Bassetti CL, Bonsignore MR, et al. Challenges and perspectives in obstructive sleep apnoea. Eur Respir J 2018; 52: 1702616

24 Sánchez-de-la-Torre M, Gozal D. Obstructive sleep apnea: in search of precision. Expert Rev Precis Med Drug Devel 2017; 2: 217-228.

25 Drager LF, McEvoy RD, Barbe F, et al. Sleep apnea and cardiovascular disease: lessons from recent trials and need for team science. Circulation 2017; 136: 1840-1850.

26 Garbarino S, Scoditti E, Lanteri P, et al. Obstructive sleep apnea with or without excessive daytime sleepiness: clinical and experimental data-driven phenotyping. Front Neurol 2018; 9: 505.

27 Pack AI. Application of personalized, predictive, preventative, and participatory (P4) medicine to obstructive sleep apnea. A roadmap for improving care? Ann Am Thorac Soc 2016; 13: 1456-1467. 